\title{
The Effects of Font Type and Spacing of Text for Online Readability and Performance
}

\author{
Nafiseh Hojjati \& Balakrishnan Muniandy \\ Universiti Sains Malaysia, Malaysia
}

\begin{abstract}
Texts are a group of letters which are printed or displayed in a particular style and size. In the course of the fast speed of technological development everywhere and expanding use of computer based instruction such as online courses, students spend more time on a computer screen than printed media. Texts have been the main element to convey messages. It has also been a significant component for learning. The main goal of this research is to measure the effects of font type and spacing of on screen text and its readability in improving and boosting the learner's ability to read easily, recall information, and enhance their reading speed and comprehension from on screen text with different topics. The readability of text on screens is necessary to ensure effective engagement in order to enhance the level of students' readability. For this purpose two font types were selected, Times New Roman (serif) and Verdana (san serif) for the respondents. Verdana was designed only for computer screens display. Readability test on a computer screen was conducted on 30 postgraduate students. Overall, the results showed that there was a significant difference between the readability of serif and san serif font type of on-screen display. The research findings suggest Verdana font type as a better choice in displaying long text for on-screen display.
\end{abstract}

Keywords: Font type; Readability; Spacing; On-screen text; Serif; San serif

\section{Introduction}

Texts are a collection of letters and words which are printed or displayed in a particular style and size. With the fast pace of technological development everywhere and expanding use of computer based instruction such as online courses, students spend more time on a computer screen than printed media (Ferrari \& Short, 2002). Texts have been the main element to convey messages across culture which has also been an important element for learning. The main goal of this research is to measure the effects of font type and spacing of on screen text and in improving and boosting the learner's ability to read easily and retain information while enhancing their reading speed and comprehension from on screen text.

This study explores the efficiency of different aspects of text such as font type (serif or san serif), and line spacing on reading speed and comprehension. The readability of text on screens is necessary to ensure effective engagement with media. Moreover, readability is also related to features and layout of text which influence the understanding of meaning that the writer intended to convey (Ambrose \& Harris, 2005). 
There are many factors which can affect or improve the ability to read text on a computer screen which including font size, blank space, text line spacing, paragraph styles, length of the line and words length. This study intends to explore the influence of on screen font type and line spacing in order to recall information and read easily. Readability can include two aspects: how well the text is placed visually and how simply the text can be understood. Worthy text should be extremely clear in order to be obviously understood by a wide range of readers.

Typical fonts can be placed into two groups: Serif and San Serif. Serif was the first font, made earlier in the era of metal type printing. Historically, the serif fonts were the most widely used, such as Venetian, Old Style (Old Face, Geralde), Transitional, Modern (Didone), and Egyptian (Rabinowitz, 2006). Serif fonts have small strokes at the end of the letters, whereas san serif fonts do not.

Different types of typefaces (fonts) have different essential levels of readability. Spacing is also vital for text to be legible. It's beneficial for the reason that it helps the eye to find a block of font as a group, and also supports the reader quickly to find the beginning of each line. In typography, control of space between words is a significant part of page design. Loose spacing have a tendency to effect pages to stream and decreasing legibility.

Seldom highlighted issues related to the text and font is readability that refers to the ease of reading, in which the common factors affecting that influence legibility of space, font size, font type. Some studies have been conducted to determine the best font-serif or san serif- in terms of readability and reading abilities of on screen. It is said that serif fonts are suitable for printed media and san serif fonts are suitable for computer screens because they are much easier and faster to read (Amdur, 2007; Berrymann, 1984; Bryan, 1996; Peck, 2003). Computer screens are very different from printed documents, as they use a resolution lower than $72 \mathrm{dpi}$, whereas printed documents use $180 \mathrm{dpi}, 300 \mathrm{dpi}$, or higher (Wilson, 2001).

Prior investigational work leads to the estimate that longer lines will be read faster, which may be moderately attributable to spending less time in scrolling actions. Though, outcomes from the legibility of print would predict faster reading at medium line lengths, reading text on a computer screen is really exhausting, and text that includes extended phrase must be escaped (Gotz, 1998). Reading from a computer screen is different from printed media. Besides, reading on screen text is $30 \%$ slower than reading printed materials (Ferrari \& Short, 2002). With regard to these limits, a number of new on screen font type have been intended specially to be suitable on screen readings (Rabinowitz, 2006). Some studies indicate no differences between the fonts whereas others recommend that san serif fonts are better for computer screens, in terms of readability (Josephson, 2008; Wilson, 2001).

\section{Font and Readability}

Font is a set of letterings that are printed or shown in a particular style and size. In computer based instructional design, selection of suitable fonts has an influence on students, specifically in terms of distinguishing and understanding the signs successfully. When the letters are put together to create words, the feature of identifying these characters is significant for perfect readability. On-screen font type, are fonts that have been considered from the start to optimally render typographic features (features such as x-height, spacing, and serifs that increase legibility) on the bitmapped screens of computers. Therefore, making efforts to overcome an understandable technical limitation of on-screen text display is necessary. 
In a study of fonts used on screen, researchers found that, the font types that were supposed to be most readable were Courier, Comic, Verdana, Georgia, and Times (Bernard, Mills, Peterson, \& Storrer, 2001). Also Bernard, Mills, Peterson, and Storrer (2001) establish that Arial, Comic, Tahoma, Verdana, Courier, Georgia were considerably chosen over the other font types, though, Times New Roman is the most common default font type for word processing packages software.

For this research, two font types were selected, specifically Times New Roman (serif) and Verdana (san serif) for the respondents. Verdana was designed only for computer screens display. Meanwhile, Times New Roman was firstly designed for print media. One-to-one these font types are commonly spread and became standard font type used for on screen and printed media (Harris, 1996). Times New Roman font type is measured to have more readability for print, and has since developed an enormously common font type for both books and documents.

The two fonts examined in this experiment (Verdana, Times New Roman) are descriptive of commonly divided serif and san serif typefaces, though; each font type is intended to function properly on two different purposes. Verdana was considered definitely to improve readability of text performing on a computer screen, although Times New Roman was intended specifically to boost readability of text printed on paper.

Serif fonts such as Times New Roman is normally observed as the most readable font family for printed text Many web designers say that san serif fonts, such as Arial or Verdana, have a better screen readability especially at small sizes than other serif fonts (Peck, 2003; Powell, 2002; Wilson, 2001).

Previous readability research has concentrated on the effects of typeface and page layout variables on reading rate and comprehension, psychological and mental human factors (Holmes, 1986). Furthermore, the research was related to reading rate and reading understanding the text (Holmes, 1986).

Readability talks about the speed and ease of understanding and comprehending the text (Mills \& Weldon, 1987; Woods, Davis, \& Scharff, 2005). Readability is a significant matter and finding the right fit between students' reading capability and text difficulty is an essential and puzzling task for teachers (Armbruster, 1977). Students have dissimilar past experiences. Every school has students who possess higher and lower average reading level. The difficulty in reading a text varies. Even though some texts can be read easily by the students, others are hard to read. Finding the right thing between the difficulty level of the text and the students' reading skills is very serious (Gunning, 2003).

Various studies (Ambrose \& Harris, 2005; Brady, 1993; Clinton, 2003; Ferrari \& Short, 2002; Gates, n.d.; Monotype, 1997) have been carried out to define the finest font, serif or san serif, in order to identify the readability for on screen text. Serif fonts are appropriate for printed media and san serif fonts are appropriate for computer screens because they are easier and faster to read. However, maximum fonts used on computer screens are actually designed for printed media. In theory, text on screen should be quite recognizable and at the same time inspiring and motivating. Selections of studies reviewed for this research indicates that learner do read text on screen when it is evolving their comprehension. Besides, several research 
outcomes suggest that reading text from the screen also helps learners to learn and recall words better.

\section{The Effects of Spacing on Readability}

A paragraph of text is formed by several lines. Those lines have two significant belongings: line length and line spacing. Every single character occupies its own horizontal space. There is an individual space before and after the character form to detach it from the end-to-end character. The space is prearranged by the type designer in the first instance (normal spacing), although it can be reformed to a loose (or open) setting or to a tight or very tight setting (to a unit, where letter characters are end-to-end). The space between characters is vital to create each shape as separate, but at the same time character forms have to be kept close enough to form a clear object: a word.

Noticeably, spacing is essential for text to be legible. Whitespace around features is known in design-speak as margin when applied to blocks of text. It's beneficial as it helps the eye to recognize a block of text as a group, and furthermore helps readers rapidly catch the start of each line. Proximity also has need of whitespace, so usage of space around all paragraphs and headers is necessity. Besides, some researchers (McLean, 1980; Tschichold, 1965; Turtschi, 1995) mention that longer lines require increased line spacing to improve readability. The least line length is to be found around 35 characters for two reasons: one is the already stated first choice of readers while reading; the other one is the position of the text (Turtschi, 1995). Spacing between the lines of a text, also impacts speed of reading on-screen (Dyson, 2004). Double spacing seems to be better than single spacing for reading (Dyson, 2004).

The wide range of study guides to choose for a single space after terminal punctuation for final and published work, with a few permitting double spacing in draft manuscripts and for specific settings based on personal preference. The 2002 study tested participants' reading speed for single and double sentence spaced passages of on-screen text. The authors stated that "the 'double space group' consistently took longer time to finish than the 'single space' group", but concluded that "there was not enough evidence to suggest that a significant difference exists" (Loh, Maribe, Shewanown, \& Radwan, 2002). Some researchers determine that medium levels of whitespace should produce higher levels of gratification and overall first choice than very solid or very spread-out use of space (Chaparro, Baker, Shaikh, Brady, \& Hull, 2004).

Studies conducted in the years 2003 and 2004 focused on analyzing on-screen single, double, and triple spacing. In both cases, the authors stated that there was inadequate sign to draw conclusion (Clinton, 2003). Ni, Branch, Chen, and Clinton attended a similar study in 2009 using equal spacing variables. The authors determined that the "results provided insufficient evidence that time and comprehension differ significantly among different conditions of spacing between sentences" (Ni, Branch, Chen, \& Clinton, 2009).

The World Wide Web reduces all repeated spaces because of the characteristics of HTML (Lupton, 2004). Even though this can be observed as a restriction of the underlying technology, and as such it doesn't suggest the same fine-grained control of spacing as other modern software. However, in digital age, many school students are still taught to strike the space bar twice between sentences when using computers, contributing to confusion regarding sentence spacing in the 21st century (Strizver, 2010). 
Researchers who support the single spacing defend that acquaintance with the current standard in books, magazines, and the Web improves readability, that double spacing looks weird in text using relative fonts (Williams, 2003). Proponents of double sentence spacing state that the extra space between sentences boosts readability by given that breaks between sentences and creating text seem more legible (Williams, 1995).

\section{Problem Statement}

Typography design for on screen is a new problem, even if rules coming from the printed press could apply, a certain number of specific features from the digital media ask to redefine exact rules (Ferrari \& Short, 2002). Accordingly, the necessity for exploration connected with font, particularly in order to improve students' reading skills to retain information and enhance their reading speed. The reason is readability on screen text is a vital element to make sure the effects of interactivity with on screen text. For on screen text design, selection of suitable fonts has an influence on students, mainly in terms of identifying and reading the symbols successfully. While the letters are set together to arrange words, the feature of distinguishing these signs or fonts is significant for perfect readability (Yoshida, 2000).

This concern is essential for the reason that readability is the significant factor affecting the output and tiredness of one's work (Hyungsuk \& Hyunseung, 2007). Additionally, writers have an accountability to design documents with suitable readability, it is essential to make sure that messages can be interact excellently to the readers (Rabinowitz, 2006).

Another problem that need to be stressed is that more and more information in the form of text is discriminated via the screen, the effect of font type and readability of on-screen text in order to improvement of reading and reader's performance. There has been limited study conducted on on-screen text readability and performance, many study have been done for printed version of font type.

\section{Research Objectives}

The purposes of this research are to distinguish which typeface such as serif and san serif has more efficiency for reading of on screen text to improve reading performances, as well as examine how line spacing can effect on readability in order to determine reading speed and comprehension, and easiness of reading on screen text.

\section{Research Questions}

The questions of the research were:

1) What is the effect of font types (Times New Roman vs. Verdana) on ease of reading?

2) What is the effect of font types (Times New Roman vs. Verdana) on retention?

3) What is the effect of font types (Times New Roman vs. Verdana) on time taken to read?

4) What is the effect of spacing (single spacing vs. double spacing) on ease of reading?

5) What is the effect of spacing (single spacing vs. double spacing) on retention?

6) What is the effect of spacing (single spacing vs. double spacing) on time taken to read? 


\section{Research Hypotheses}

$\mathrm{HO}_{1}$ : There is no significant difference in the ease of reading when Times New Roman is used compared to Verdana.

$\mathrm{HO}_{2}$ : There is no significant difference in the retention when Times New Roman is used compared to Verdana.

$\mathrm{HO}_{3}$ : There is no significant difference in time taken to read when Times New Roman is used compared to Verdana.

$\mathrm{HO}_{4}$ : There is no significant difference in the ease of reading when using single spacing compared to double spacing.

$\mathrm{HO}_{5}$ : There is no significant difference in the retention when using single spacing compared to double spacing.

$\mathrm{HO}_{6}$ : There is no significant difference in time taken to read when using single spacing compared to double spacing.

\section{Methodology}

\section{Sample}

The participants selected for this study were from a Malaysian University. A total of 30 international postgraduate students involved in this study. These students were randomly chosen for data analysis purposes.

\section{Research Design}

A repeated experimental design was used to test the effects of the independent variables onscreen font types upon the dependent variables of ease of reading and reading comprehension and speed. The variables contain of two different groups of text; serif and san serif font type. The font types chosen for this study were Times New Roman and Verdana.

\section{Instrumentation}

Four reading passages or text blocks, with containing 200 words at the same level of difficulty were prepared. Two expert lecturers from a Malaysian university reviewed and validated these four text blocks before the instrument was developed. The reading text blocks as exposed in Figure 1 and Figure 2 below used serif and san serif fonts with single and double spacing.

Each text block contained the different topic; this was also validated by a specialist instructor. Experiments were carried out to measure the readability of font type and spacing on reading on-screen text readability and performance. 


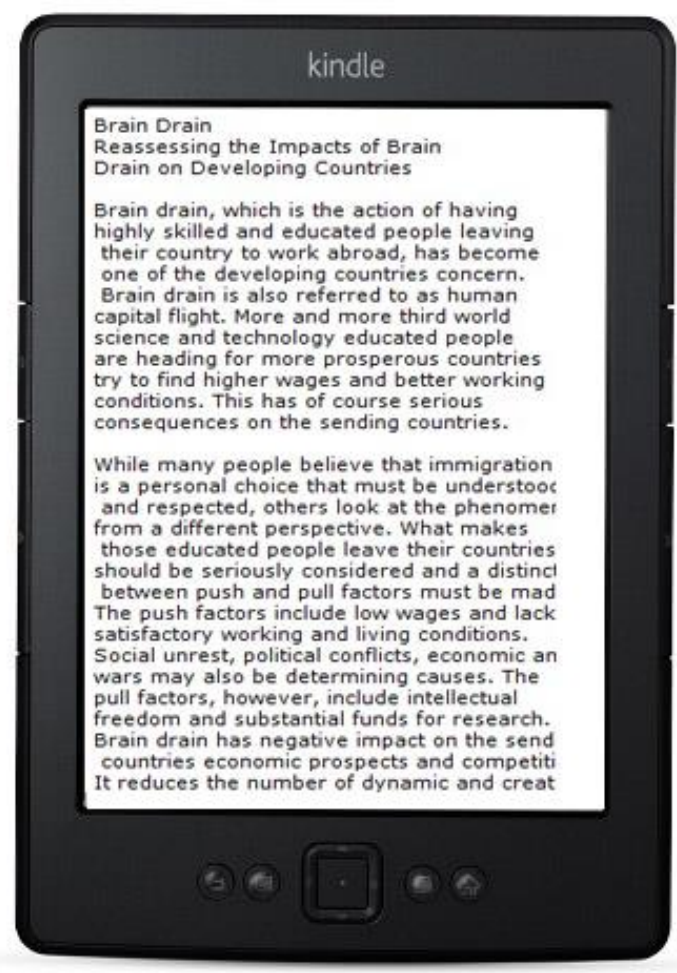

Figure 1. Verdana, Single Space

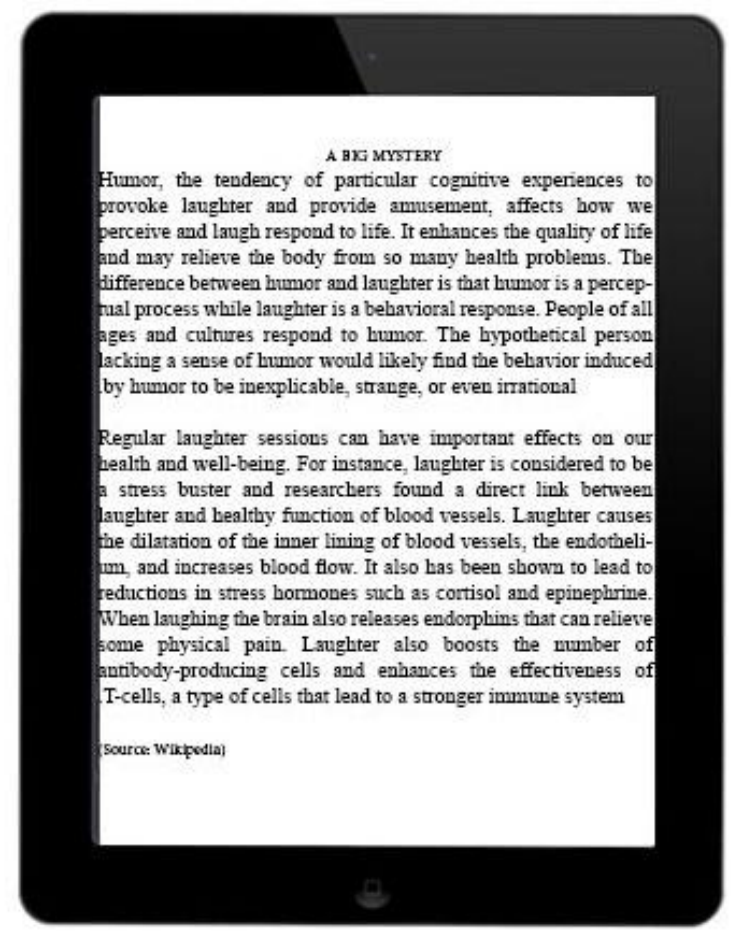

Figure 2. Times New Roman, Single Space 


\section{Research Procedures}

Respondents were randomly assigned to read four passages containing 200 words at the equal level of difficulty, with different font type and different spacing. For each student, time was taken in order to their reading speed to identify which font type by which spacing is easier to read. At the end of the each text block they have to answer a few questions in order to examine through which font type they can recall information. They were asked to read each passage. After reading each passage the respondents should answer each question that related to passage. Respondents weren't permitted to go back to the passage to look through passage.

Demographic data were collected to demonstrate their age, their level of postgraduate study, level of the usage of computer and the amount of time that they spend reading on-screen text. All text passage was fixed to a standard 12-point size.

\section{Data Analysis}

The data analyzing were based on the research questions, the respondents were a quite variant group in terms of gender, age, hours of computer use, and computer proficiency. For data analysis two groups of respondents were chosen. The majority of the study respondents were female. In addition, a large majority of the respondents had spent more than 6 hours on using computer. Four text blocks in Part B of the questionnaire were designed to elicit the respondent's preferences to ward reading academic texts on a computer screen for two purposes: reading for on-screen text with different font type and with different line spacing. The respondents were asked to indicate their level of agreement on each of four blocks text on questionnaire.

\section{Findings}

Dependent t-test was used to examine the degree of statistical difference and magnitude in students' responses. In this research the font type size used for the passages was 12 pt.as this font size was considered appropriate, wide range of web sites use $12 \mathrm{pt}$. font size (Bernard, Mills, Peterson, \& Storrer, 2001). The t-test was used to test whether there were significant differences in the readability of on- screen text between serif and san serif font's types and spacing. Results from Part One of the questionnaire showed that the respondents have a meaningful preference for reading academic texts on a computer screen. Part Two of the questionnaire involved two sections. The first section measures the students' performances of on-screen reading.

The final questions were designed to examine the respondents' level of agreement as to what they prefer to use to read texts with on a computer screen under the given conditions. The results showed that the mean differences for four items were statistically significant. Using a probability $=0.05$ as a convenient "level of significance" for making a decision whether to reject the null hypothesis or not. Accordingly, in this study one should reject the hypothesis based on to test the hypothesis which was 0.871 between single space Times New Roman vs. 
Verdana single space for retention and the level of significance for time taken between Times New Roman single space vs. Verdana single space was 0.253 .

As well, the level of significance between double Times new roman vs. Verdana double space for retention was 0.025 and the level of significance of time taken between double space Times new roman vs. Verdana double space was 0.001 . The results show that the differences toward on-screen reading between the two different font type such as serif and san serif (Times New Roan vs. Verdana) with different spacing (Double spacing vs. Single spacing) did differ much.

Table1. Respondents' Font Type Preference

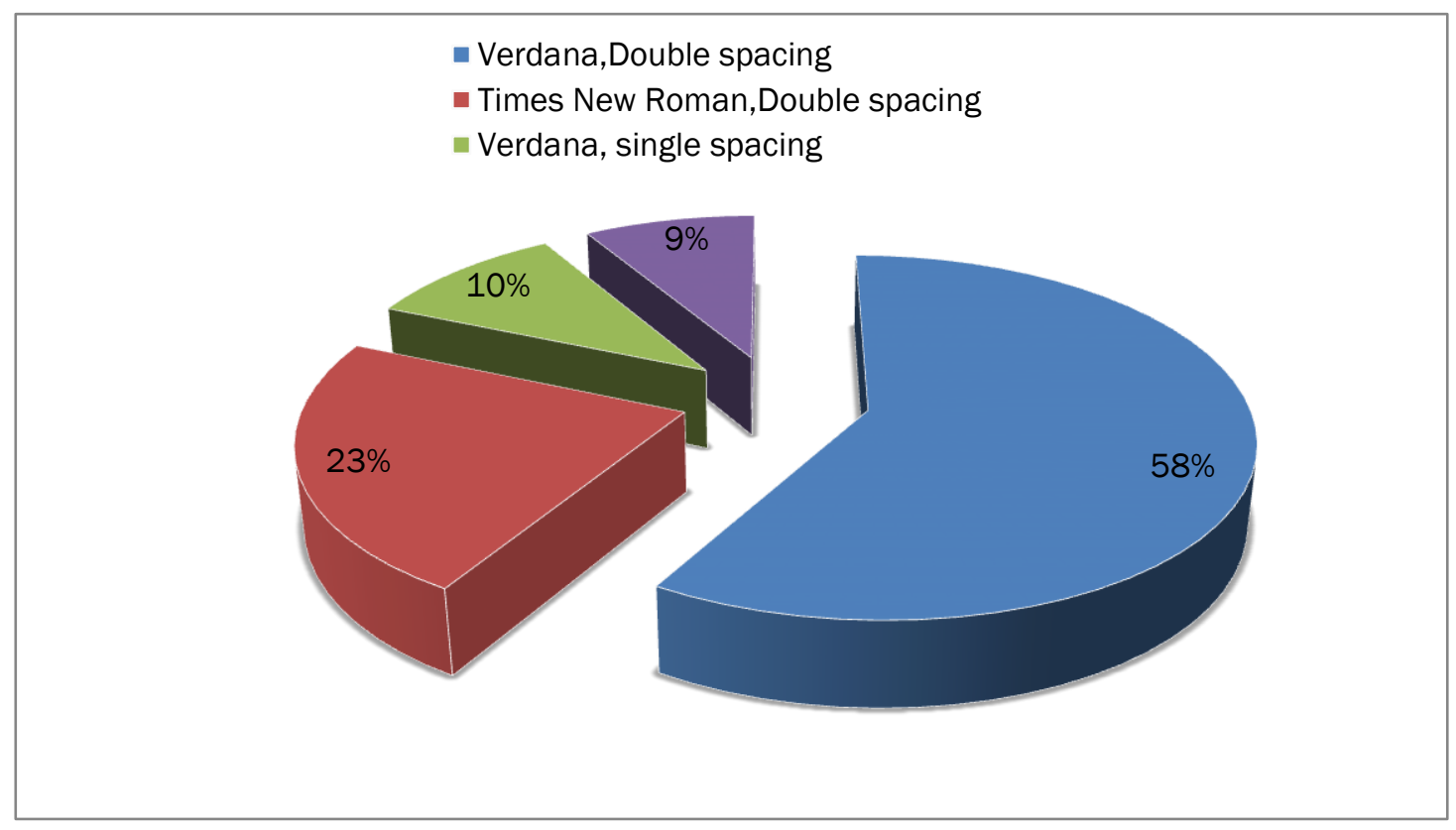

Table 2. Respondents Text Block Preference for Easy to Recall

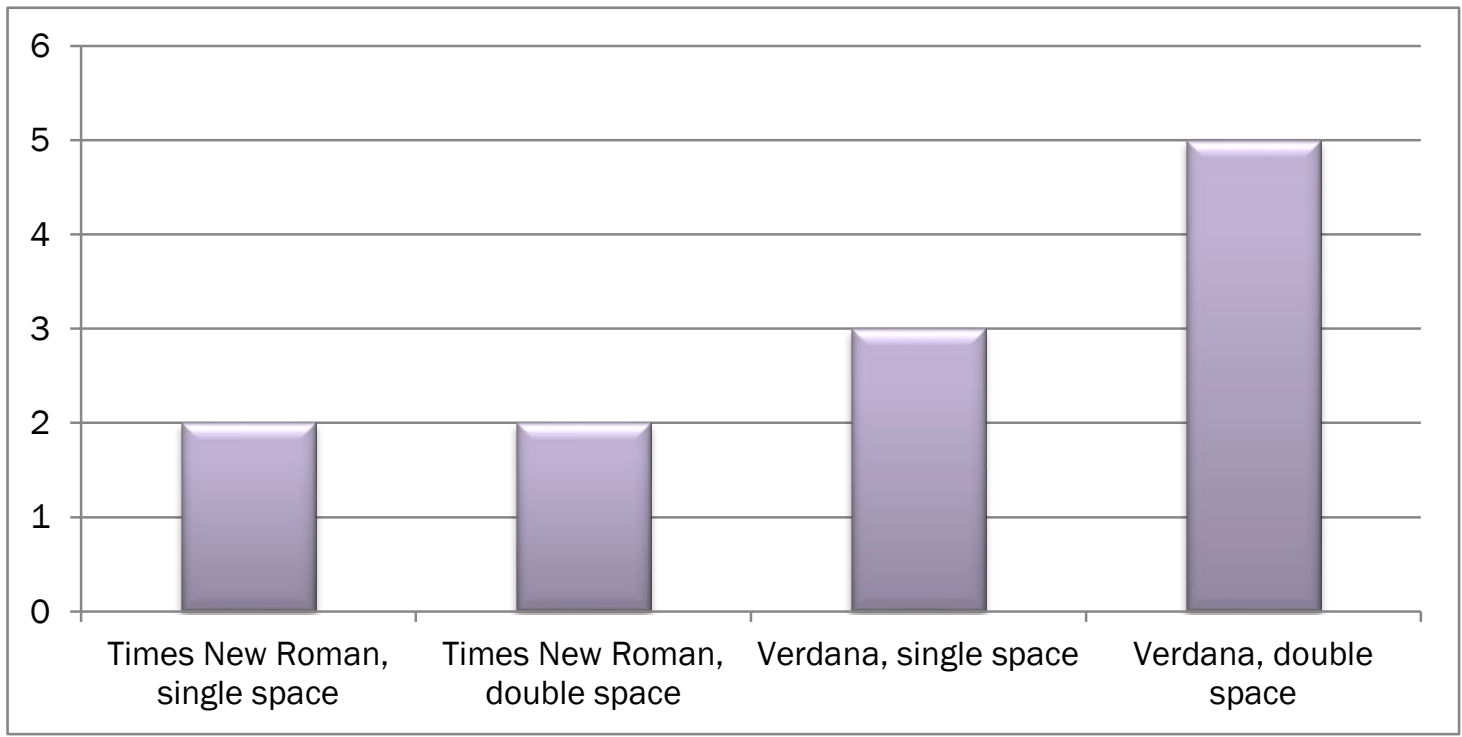


The respondents strongly agreed that they read texts blocks number 4 (Verdana with double spacing) on screen easier than other text blocks. On the other hand, the respondents also showed a confirmatory which they prefer double spacing rather than single spacing for onscreen reading purposes. Result from the dependent $t$-test shows that there was a significant main effect of line length on ease of reading, as well respondents prefer to reading on- screen text block with Verdana font type and double spacing in order to ease of reading for readers and easy to recall the text. Students had relatively average level of engagement in on-screen reading they tended to read texts on-screen for a longer time and read more section of texts with proper font type and line spacing in terms of not deciding whether to print out online materials.

Table 3. Results of Paired T-Test and Time Taken

\begin{tabular}{lccc} 
Time Taken & t & Sig. & d \\
\hline Times New Roman, single space vs. Verdana, single space & 6.117 & 0.000 & 29 \\
Times New Roman, double space vs. Verdana, double space & 5.572 & 0.000 & 29 \\
\hline
\end{tabular}

Table 4. Results of Paired t-Test and Readability

\begin{tabular}{lccc}
\hline Readability & t & Sig. & $\mathrm{d}$ \\
\hline & & & \\
Times New Roman, single space vs. Verdana, single space & 4.065 & 0.000 & .29 \\
Times New Roman, double space vs. Verdana, double space & 2.971 & 0.006 & .29 \\
\hline
\end{tabular}

The results indicate that the consideration toward two fonts type; Times New Roman single space and double space vs. Verdana single space and double space, on-screen reading between these two purposes did differ much. When measuring the effect of font type on readability and time taken for each font type, the significance of difference was fairly high. Moreover, in a study of fonts used on screen, researchers found that, the font types that were supposed to being most readable were Courier, Comic, Verdana, Georgia, and Times (Bernard, Mills, Peterson, \& Storrer, 2001).

Furthermore, Bernard, Mills, Peterson, and Storrer (2001) establish that Arial, Comic, Tahoma, Verdana, Courier, Georgia were considerably chosen over the other font types, though, that Times New Roman is the most common default font type for word processing packages software. Letters help to increase the readability of text. Though, the font type, serif or san serif that has a worthy readability of text on a computer screen is quiet doubtful (Amdur, 2007). Recent studies have showed unpredictable results, which font type is finest for on screen. Some fonts, such as Verdana, Tahoma, and Georgia, were advanced specially for use on the screen (Font readability, 2013). 
The san serif font, Verdana, was definitely designed for showing on-screens. Verdana was intended to be readable on computer screens by having extensive letter spacing and a large $x-$ height (Boyarski, Neuwirth, Forlizzi, \& Regl, 1998). Verdana does entirety right on screen; it has a large $x$-height consequently fonts look bigger, yet not so big that it's hard to tell the lowercase from the uppercase or that it looks packed in apps such as web browsers that don't have adjustable leading (Harris, 1998).

Verdana font type does a number of things to boost readability: its $x$-height is big, characters are long (extra set width), enlarged letter spacing, bolds are enhanced. In addition Verdana is designed for on-screen usage due to the fact that Verdana have exact letter spacing which ensures that letters never touches. Several researchers believe that reading from a screen is considerably slower than reading from paper-based texts, but this study shown that with correct spacing between lines it can take short time reading with double spacing than single spacing.

\section{Discussion and Conclusion}

Findings of text readability and reading performances between serif (Times New Roman) and san serif (Verdana) fonts showed that the difference between these procedures is significant. Accordingly, this finding further supports the important new role of san serif fonts, (i.e. Verdana), in demonstrating more readable text on the computer screen that competitors recognized the character of serif fonts (i.e. Time New Roman) for the equal presenting determination. In addition, the serif fonts have been specifically designed for printed media and not for show on the computer screen (Peck, 2003), whereas some san serif fonts, such as Verdana, have been designed to fit into the computer screen that increases text readability (Harris, 1998).

However, most of today's computer screens have the capability to show all type of fonts visibly on similarity with the printed media. In addition, these findings demonstrate that there are significant differences in terms of readability between Times New Roman and Verdana fonts on the computer screen (Peck, 2003; Powell, 2002). Overall, the respondents of this study preferred Verdana font type with double spacing to Times New Roman font type.

Verdana has more readability as it is more clear, simple, with a high $\mathrm{x}$-height, and with a width set of the right dimensions to support progress of the readability of the on-screen text (Peck, 2003). Extra significant characteristic that has been established in refining Verdana text readability is that its font letters are not in contact with each other and this exclusive feature supports to increase readability on the computer screen.

As discussed earlier, Times New Roman font type was initially developed for printed media (Ambrose \& Harris, 2005). Times New Roman was intended to maintain the legibility of text, regardless of the high amount of letterings contained in a single line of text (Conover, 2003). Therefore, this font has frequently been used in newsprint to put up more thick text in a limited space.

In this study, the findings show that there are significant differences in terms of readability and reading performances of text in Times New Roman (serif font) and Verdana (san serif). Accordingly, it can support the claim that san serifs have better computer screen readability than serif. Earlier, (Bernard, Mills, Peterson, \& Storrer, 2001) had found that Times New 
Roman allowed faster reading but Verdana was the font that selected by the research respondents.

In conclusion, the finding of this study provides additional evidence on the efficiency of serif and san serif fonts, for on-screen presentation purpose. Found on the findings and literature review, this study recommends Verdana as the best choice for on-screen text reading.

This study found that there was significant difference in text readability and reading performances on the computer screen text reading between serif (Times New Roman) and san serif (Verdana) fonts. Additionally, the first font type which is designed for the printing and the latter font is designed for the on-screen, offer different readability and reading performances for on -screen text in this study.

The standard repetition of using serif and san serif fonts, specifically Times New Roman and Verdana, for on- screen text reading would be preferable for reading long text on on-screen. However, Times New Roman should be considered that is in especially for the print media font's category. On the other hand, certain assumption is not applicable at this point since the study involves only 30 international respondents from a Malaysian university with different level of postgraduate study; master and doctoral.

Future studies may consider longer term assessments, using different media over a period of days, weeks, or months and should test longer passages; if possible, entire textbooks for comprehension differences. Future studies may also involve different topics to see if age, gender, or educational background would affect performance. Long term comprehension effects must also be tested to see if retention differs based on design. The results of such studies may provide interesting results.

New studies may also look at the essential time taken to find information in more or longer text blocks during on-screen reading, examine the retention ability based on reading for different font types of on-screen, and demonstrate how well-organized respondents notice the readability.

\section{References}

Ambrose, G. \& Harris, P. (2006). Basics design 03: Typography. Lousanne, Switzerland: AVA Publishing.

Ambrose, G. \& Harris, P. (2005). Typography. Lousanne, Switzerland: AVA Publishing.

Amdur, D. (2007). Typographic design in the digital studio: Design concepts. Clifton Park, NY: Thomson/Delmar Learning.

Armbruster, B. B. (1977). Matching readers and texts: The continuing quest. In D. Lapp, J. Flood, and N. Farnan (Eds.), Content area reading and learning ( $3^{\text {rd }}$ ed.). New York: Erlbaum.

Bernard, M., Mills, M., Peterson, M., \& Storrer, K. (2001). A comparison of popular online fonts: Which is best and when? Retrieved on 12 February 2014 from http://psychology.wichita. edu/surl/usabilitynews/3S/font.htm

Berrymann, G. (1984). Notes on graphic design and visual. Los Altos, CA: Kaufman. 
Boyarski, D., Neuwirth, C., Forlizzi, J., \& Regl, S. (1998). A study of fonts designed for screen display. Proceedings of the SIGCHI Conference on Human Factors in Computing Systems (pp. 87-94). New York: ACM Press/Addison-Wesley.

Bryan, M. (1996). Digital typography sourcebook. Toronto, Canada: John Wiley \& Sons.

Brady, P. ( 1993). Using type right: 121 basic no-nonsense rules for working with type. Chicago, IL: NTC Publishing Group.

Chaparro, B., Baker, J., Shaikh, A., Brady, L., \& Hull, S. (2004). Reading online text: A comparison of four white space layouts. Retrieved on 9 August 2013 from http://psychology.wichita.edu/surl/usabilitynews/62/whitespace.htm

Clinton, G. (2003). Statistically significant differences between reading time of single and double spaces passages. AECT Leadership \& Technology International Convention. Anaheim, CA.

Conover, C. (2003). Designing for print: An in-depth guide to planning creating and producing successful. Hoboken, NJ: John Wiley \& Sons.

Dyson, M. (2004). How physical text layout affects reading from screen. Behaviour \& Information Technology, 23(6), 377-393.

Ferrari, T. \& Short, C. (2002). Legibility and readability. Retrieved on 9 August 2013 from http://bigital.com.

Font readability. (2013). Retrieved on 12 February 2014 from www.Icsc.edu

Gates, B. (n.d.). Microsoft Corporation. Retrieved on 12 February 2014 from http://www. microsoft.com/typography/web/default.htm

Gotz, V. (1998). Color \& type for the screen. Hove, East Sussex, England: Rotovision.

Gunning, T. (2003). The role of readability in today's classrooms. Language Disorders, 23(3), 175-188.

Harris, W. (1996). The best faces for the screen. Retrieved on 9 August 2013 from http://www. will-haris.com/ typoscrn.htm.

Harris, w. (1998). Typefaces designed for the screen. Retrieved on 9 August 2013 from http://www.will-hariss.com/Verdana-Georgia

Holmes, J. (1986). Formatting variables and typeface variations of dot-matrix print and their effect on reading comprehension and reading speed. Retrieved on 12 February 2014 from http://scholar.lib.vt.edu/theses/available/etd-02032004-161548/

Hyungsuk, J. \& Hyunseung, C. (2007, May). An interactive user interface for text display. Proceedings of 7th International Conference on Computational Science. Beijing, China.

Josephson, J. (2008). Keeping your readers' eyes on the screen: An eye-tracking study comparing san serif and serif typefaces. Visual Communication Quarterly, 15(1-2), 67-79.

Loh, C., Maribe B., R., Shewanown, S., \& Radwan, A. (2002). The effect of text spacing after the period on time for on-screen reading tasks. Selected Readings of the IVLA Annual Conference. IVLA.

Lupton, E. (2004). Thinking with type. New York: Princeton Architectural Press.

McLean, R. (1980). The Thames and Hudson manual of typography. London: Thames. 
Mills, C. \& Weldon, L. (1987). Reading text from computer screens. ACM Computing Surveys, 19(4), 329-357.

Monotype. (1997). Web fonts for Microsoft. Retrieved from http://www.monotype.com/ html/news/nr_ms_web.html

$\mathrm{Ni}$, X., Branch, R., Chen, K. C., \& Clinton, G. (2009). The effects of text spacing on screen reading time and comprehension. International Journal of Instructional Media, 36(4), 383-390.

Peck, W. (2003). Great web typography. New York: Wiley.

Powell, A. (2002). Web design: The complete reference. Osborne: McGraw-Hill.

Rabinowitz , T. (2006). Exploring typography. Clifton Park, NY: Thomson Delmar Learning.

Strizver, I. (2010). Double spaces between sentences ... Not! U\&Ic: Upper and Lowercase Magazine Online; Issue 41.1.1. International Typeface Organization and Monotype Imaging. Retrieved on 18 April 2014 from http://www.itcfonts.com/ulc/4111/ Doublespace.htm

Tschichold, J. (1965). Meisterbuch der schrift. Ravensburg: Otto Maier.

Turtschi , R. (1995). Praktische typographe: Gestalten mit dem personal computer. Sulgen, Germany: Niggli.

Williams, R. (1995). The PC is not a typewriter. Berkeley, CA: Peachpit.

Williams, R. (2003). The Mac is not a typewriter: A style manual for creating professional-level type on your Macintosh. Berkeley, CA: Peachpit.

Wilson, R. (2001). Text font readability study. Retrieved on 6 April 2013 from http://www. wilsonweb.com/wmt6/html-email-fonts.htm.

Woods, R., Davis, K., \& Scharff, L. (2005). Effects of typeface and font size on legibility for children. American Journal of Psychological Research, 1(1), 86-102.

Yoshida, K. (2000). Avoiding typeface error. Society for Technical Communication Proceedings. Retrieved on 6 April 2013 from http://www.stc.org/confproceed/2000/PDFs/ 00006.pdf

Correspondence: Nafiseh Hojjati, School of Instructional Technology and Multimedia, Universiti Sains Malaysia, Penang, Malaysia 